\title{
Postoperative monitoring of free flap reconstruction: A comparison of external Doppler ultrasonography and the implantable Doppler probe
}

\author{
Rayaad C Hosein MD, Agustin Cornejo MD, Howard T Wang MD
}

RC Hosein, A Cornejo, HT Wang. Postoperative monitoring of free flap reconstruction: A comparison of external Doppler ultrasonography and the implantable Doppler probe. Plast Surg 2016;24(1):11-19.

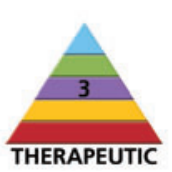

HYPOTHESIS: The time to detection of vascular compromise and the postoperative time to re-exploration are shorter using the implantable Doppler (ID) probe, thereby resulting in earlier surgical re-exploration and a higher flap salvage rate.

METHODS: A single-centre experience with 176 consecutive free flap reconstructions in 167 patients from 2000 to 2008 in a university-based teaching hospital by retrospective chart review is presented.

RESULTS: There was a significant difference in overall flap survival (ID 98.0\%, external Doppler [ED] 89.3\%) and total flap loss (ID 2.0\%, ED $10.7 \%)$ between the two groups $(\mathrm{P}=0.03)$. The difference in flap salvage rate was not significant (ID 90.9\%, ED 63.6\%; P=0.068). The false-positive (ID 0\%, ED 3\%; $\mathrm{P}=0.18$ ) and false-negative rates (ID 0.0\%, $\mathrm{ED} 4.5 \%$; $\mathrm{P}=1.0$ ) were not significantly different. There was also a lower median postoperative time to re-exploration for the ID group, from $48 \mathrm{~h}$ to one week after initial surgery (ID 74.5 h, ED 136.8 h; P=0.05).

CONCLUSION: The present analysis revealed a potential benefit for the ID probe in the postoperative monitoring of free tissue transfers.

Key Words: Complications; Doppler; External; Free flap; Handheld; Implantable; Internal; Monitoring; Reconstruction

$\mathrm{M}$ icrovascular free flap reconstruction is a versatile option for coverage of a multitude of large tissue defects in fields that include surgical oncology, trauma, orthopedics, head and neck surgery, and breast reconstruction. Success rates quoted in the literature range from $91 \%$ to $99 \%$ and are likely due to advances in the development of microsurgical equipment, more prevalent surgical expertise and improved surgical materials and instrumentation (1). Despite the success of free tissue transfers, a small number of flap-related complications continue to occur. Six percent to $14 \%$ of free flaps are re-explored due to vascular complications $(2,3)$. They often present early in the postoperative course, with $95 \%$ of failing flaps presenting within $72 \mathrm{~h}$ of surgery $(2,4)$. Postoperative monitoring of free flaps is usually most intense in this period. Flaps with vascular compromise detected early are promptly re-explored resulting in a higher flap salvage rate (2). Nonvascular complications are usually wound related and present later in the postoperative course (5). However, flaps with vascular compromise detected in the late postoperative period have a high likelihood of failure due to the associated lengthy ischemia times and the onset of irreversible tissue loss (3). Cusano and Fernandes (3) documented that nonburied flaps with vascular compromise clinically detected within $48 \mathrm{~h}$ after surgery have a $77 \%$ flap salvage rate whereas failure of buried flaps went unrecognized until a wound complication manifested (generally $>7$ days postoperatively). This resulted in later re-exploration and a flap salvage rate of $0 \%$ (3). Bui et al (1) found in their retrospective review of 1193 flaps that $76 \%$ of head and neck flaps requiring

\author{
La surveillance postopératoire de la reconstruction \\ par lambeau libre : une comparaison entre \\ l'échographie Doppler et la sonde Doppler \\ implantable
}

HYPOTHÈSE : Le délai entre la détection d'une atteinte vasculaire et la réexploration postopératoire est plus court à l'aide de la sonde Doppler implantable (DI), ce qui favorise une réexploration chirurgicale plus rapide et un taux plus élevé de sauvegarde des lambeaux.

MÉTHODOLOGIE : Les auteurs présentent l'expérience monocentrique de 176 reconstructions consécutives par lambeaux libres chez 167 patients entre 2000 à 2008 dans un hôpital universitaire au moyen d'une analyse de leurs dossiers.

RÉSULTATS : Il y avait une différence importante dans la survie globale des lambeaux (DI 98,0\%, Doppler externe [DE] 89,3\%) et perte totale des lambeaux (DI 2,0\%, DE 10,7 \%) entre les deux groupes ( $\mathrm{P}=0,03)$. La différence en matière de taux de sauvegarde des lambeaux n'était pas significative (DI 90,9\%, DE 63,6\%; P=0,068). Les taux de résultats faussement positifs (DI $0 \%, \mathrm{DE} 3 \% ; \mathrm{P}=0,18$ ) et de résultats faussement négatifs (DI $0,0 \%, D E 4,5 \% ; P=1,0)$ n'étaient pas sensiblement différents. Le délai postopératoire médian avant la réexploration était également plus court dans le groupe DI, soit de 48 heures à une semaine après l'opération initiale (DI 74,5 h, DE 136,8 h; P=0,05).

CONCLUSION : La présente analyse a révélé l'avantage potentiel de la sonde DI lors de la surveillance postopératoire des transferts de tissus libres.

re-exploration did so within five days of the initial surgery. Hence, the survival of flaps with vascular compromise is inversely proportional to time to detection of the defect and time to re-exploration to salvage the failing flap $(3,6)$. Therefore, monitoring techniques that facilitate early detection of vascular compromise are essential in the postoperative care of these patients.

Traditionally, clinical monitoring of free flaps in the postoperative period was considered to be the gold standard. This required a clinician to monitor the flap's physical characteristics for colour, turgor, swelling, capillary refill time, temperature, bleeding characteristics after a pin prick or a combination of these approaches $(1,3)$. Some surgeons would also include use of the external or handheld Doppler ultrasound device (ED) in this category. However, in the pursuit of techniques to reduce the time to detection of flaps with vascular compromise, various newer modalities have been developed such as the implantable Doppler ultrasound probe (ID), pulse oximetry, laser Doppler flowmetry, colour Duplex sonography, near infrared spectroscopy, visible light spectroscopy, and tissue $\mathrm{pH}$ monitoring with microdialysis (4). While previous surveys have shown that the adjunctive use of postoperative monitoring devices (including the ID and the ED) to be superior to clinical monitoring in improving flap salvage rates, whether one device is better than another continues to be a topic of much debate in the surgical literature (6-8).

In 1975, Creech and Miller outlined the criteria they considered essential for the "ideal" free flap monitoring device $(6,9)$. These were

Division of Plastic and Reconstructive Surgery, Department of Surgery, University of Texas Health Science Center at San Antonio, San Antonio, Texas, USA

Correspondence: Dr Howard T Wang, Division of Plastic and Reconstructive Surgery, 7703 Floyd Curl Drive, San Antonio, Texas, USA 782293900. Telephone 210-567-6936,fax 210-567-6390,e-mail wanght@uthscsa.edu 
TABLE 1

Patient demographics according to monitoring device

\begin{tabular}{|c|c|c|c|c|}
\hline Demographics & $\begin{array}{l}\text { Internal } \\
\text { Doppler }\end{array}$ & $\begin{array}{l}\text { External } \\
\text { Doppler }\end{array}$ & Total & $\mathbf{P}$ \\
\hline Patients & $96(57.5)$ & $71(42.5)$ & 167 & 0.32 \\
\hline Flaps & $101(57.4)$ & $75(42.6)$ & 176 & 0.56 \\
\hline Age, years, mean $\pm S D$ & $46.5 \pm 17.2$ & $44.1 \pm 15.6$ & $\mathrm{n} / \mathrm{a}$ & 0.34 \\
\hline \multicolumn{5}{|l|}{ Sex by flap number } \\
\hline Male & 55 (31.3) & $39(22.2)$ & 94 & 0.76 \\
\hline Female & $46(26.1)$ & $36(20.5)$ & 82 & 0.76 \\
\hline $\begin{array}{l}\text { Body mass index, } \mathrm{Kg} / \mathrm{m}^{2} \text {, mean } \\
\pm \mathrm{SD}\end{array}$ & $26.6 \pm 5.9$ & $29.3 \pm 7.0$ & $\mathrm{n} / \mathrm{a}$ & 0.06 \\
\hline \multicolumn{5}{|l|}{ Race by flap number } \\
\hline Hispanic & $19(10.8)$ & $22(12.5)$ & 41 & 0.11 \\
\hline White & 65 (36.9) & $40(22.7)$ & 105 & 0.16 \\
\hline Black & $7(4.0)$ & $8(4.5)$ & 15 & 0.43 \\
\hline Asian & $0(0.0)$ & $1(0.6)$ & 1 & 0.43 \\
\hline Multirace & $10(5.7)$ & $4(2.3)$ & 14 & 0.40 \\
\hline \multicolumn{5}{|l|}{ Comorbidities } \\
\hline Current tobacco use & $40(22.7)$ & $23(13.1)$ & 63 & 0.27 \\
\hline Hypertension & $23(13.1)$ & $13(7.4)$ & 36 & 0.45 \\
\hline Diabetes & $8(4.5)$ & $9(5.1)$ & 17 & 0.44 \\
\hline Coronary artery disease & $4(2.3)$ & $4(2.3)$ & 8 & 0.72 \\
\hline Steroid use & $3(1.7)$ & $1(0.6)$ & 4 & 0.64 \\
\hline Preoperative radiotherapy & $12(6.8)$ & $4(2.3)$ & 16 & 0.19 \\
\hline Preoperative chemotherapy & $14(8.0)$ & $3(1.7)$ & 17 & 0.06 \\
\hline Serum albumin, $g / d L$, mean \pm SD & $3.5 \pm 0.7$ & $3.8 \pm 0.8$ & $\mathrm{n} / \mathrm{a}$ & 0.15 \\
\hline \multicolumn{5}{|l|}{ Indication for reconstruction } \\
\hline Elective & $78(77.2)$ & $50(66.7)$ & 128 & 0.13 \\
\hline Trauma & $23(22.8)$ & $25(33.3)$ & 48 & 0.13 \\
\hline \multicolumn{5}{|c|}{ American Society of Anesthesiologists class } \\
\hline 1 & $1(0.6)$ & $3(1.8)$ & 4 & 0.31 \\
\hline 2 & $48(28.1)$ & $44(25.7)$ & 92 & 0.53 \\
\hline 3 & $47(27.5)$ & $22(12.9)$ & 69 & 0.05 \\
\hline 4 & $3(1.8)$ & $3(1.8)$ & 6 & 0.70 \\
\hline
\end{tabular}

Data presented as $n$ (\%) unless otherwise indicated. n/a Not applicable

later supplemented by Jones in 1983 and include safety to the patient and flap, applicability to all flap types, rapid response to blood flow changes, accuracy, affordability and ease of interpretation (4). The ID probe fulfills most of these criteria (9). Its continuous data stream also makes a rapid response to suspected flap compromise possible (9). Additionally, the ID has an advantage in monitoring buried flaps where clinical or ED monitoring would be virtually impossible without exteriorizing a vascular component or creating a surgical window for monitoring on the surface of the skin above the flap $(10,11)$. Although there is an additional cost associated with its use, many authors have justified the expense in comparison to the huge cost associated with flap failure (9). Rozen et al (12) performed a versatile cost benefit analysis of the ID and found the expenditure of US $\$ 20,000$ would potentiate the salvage of one additional flap, a cost that would be far outweighed by the expenditure for the surgical management of a failed free flap. In addition to the surgical cost of replacing the flap, the physical and emotional devastation to the patient and the impact on the surgeon's operative record cannot be overstated (13). At this time, only $16 \%$ of surgeons utilize the ID in routine practice compared with $75 \%$ who use the ED device (14).

The purpose of the present retrospective study was to compare the effectiveness of the ID probe with that of the ED device in the postoperative monitoring of free flaps. We hypothesized that the time to detection of vascular compromise and the postoperative time to reexploration are shorter with the ID probe compared with the ED device thereby resulting in a higher flap salvage rate.
TABLE 2

Flap type according to monitoring device

\begin{tabular}{lcccc}
\hline Flap type & $\begin{array}{c}\text { Internal } \\
\text { Doppler }\end{array}$ & $\begin{array}{c}\text { External } \\
\text { Doppler }\end{array}$ & Total & $\mathbf{P}$ \\
\hline Myocutaneous & $51(50.5)$ & $64(85.3)$ & 115 & 0.0001 \\
Gracillis & $4(2.3)$ & $0(0.0)$ & 4 & 0.14 \\
Serratus & $0(0.0)$ & $5(2.8)$ & 5 & 0.07 \\
Rectus abdominis & $36(20.5)$ & $42(23.9)$ & 78 & 0.01 \\
Fasciocutaneous & $39(38.6)$ & $3(4.0)$ & 42 & 0.0001 \\
Anterolateral thigh flap & $30(17.0)$ & $1(0.6)$ & 31 & 0.0001 \\
Radial forearm & $4(2.3)$ & $2(1.1)$ & 6 & 1.00 \\
Scapular & $1(0.6)$ & $0(0.0)$ & 1 & 1.00 \\
DIEP & $4(2.3)$ & $0(0.0)$ & 4 & 0.14 \\
Osteocutaneous & $11(10.9)$ & $8(10.7)$ & 19 & 1.0 \\
Parascapular & $0(0.0)$ & $1(0.6)$ & 1 & 0.43 \\
Fibular & $11(6.3)$ & $7(4.0)$ & 18 & 0.81 \\
\hline DIEP Deep inferior epigastric & perforator flap & & &
\end{tabular}

DIEP Deep inferior epigastric perforator flap

\section{METHODS}

The study was approved by the Institutional Review Board at the University of Texas Health Science Center at San Antonio (Texas, USA). A retrospective chart review of 167 consecutive patients undergoing 176 microsurgical free tissue transfers from January 1, 2000 to December 12, 2008 at University Hospital in San Antonio, Texas, was performed. The surgical procedures were performed by two senior head and neck surgeons and four senior plastic and reconstructive surgeons, thereby minimizing temporal bias related to the practitioners' experience levels. This institution is also an experienced microsurgical centre performing a wide range of such procedures.

Electronic medical records at University Hospital were screened in the given time period using International Classification of Diseases and Current Procedural Terminology codes consistent with free tissue transfers. All patients with free flap reconstructions were included as subjects in the study. Demographic, intraoperative and postoperative data were obtained from the medical records. Each patient's chart was reviewed to determine age, sex, body mass index, preoperative medical history, nutritional status, American Society of Anesthesiologists classification and history of steroid use, chemotherapy and radiotherapy. The operative report was reviewed to determine whether the procedure was elective or due to traumatic injury, the flap used for the reconstruction, total operative time, primary flap ischemia time, fluid administration, estimated blood loss, the administration of blood for transfusion, use of venous couplers and need for intraoperative revision. Postoperative data included the monitoring technique used (ID versus ED), anticoagulation regimen, the use of vasopressors, the administration of blood for transfusion, urine output $(\mathrm{mL} / \mathrm{h})$, peripheral oxygen saturation $<92 \%$, body temperature $>101.5 \mathrm{~F}$ and mean arterial pressure $<60 \mathrm{mmHg}$ for the first $72 \mathrm{~h}$ after surgery.

\section{Definitions and variables}

Primary ischemia begins when the surgeon transects the vascular pedicle (15). This is the time when the flap is inset onto the recipient site and the vascular anastomosis is performed (15). Secondary ischemia occurs when the vascular pedicle becomes compromised (15). This generally requires re-exploration to salvage the flap thereby preserving flap viability. Four operative parameters were defined in the following manner: operative time was defined as the period from the start of the operation by the surgeon to the end time; time to detection of a complication was defined as the period from the end of the operation to the time the complication was first documented in the medical chart; and time to reoperation was defined as the period from the first documentation of a suspected complication to the anesthesia start time. In addition, the sum of the time to complication and the time to reoperation was calculated to analyze the postoperative time to reexploration of a suspected failing free flap. 
TABLE 3

Intraoperative and postoperative events according to monitoring device

\begin{tabular}{|c|c|c|c|c|}
\hline & $\begin{array}{l}\text { Internal } \\
\text { Doppler }\end{array}$ & $\begin{array}{l}\text { External } \\
\text { Doppler }\end{array}$ & $\begin{array}{c}\text { Total, } \\
\mathrm{n}\end{array}$ & $\mathbf{P}$ \\
\hline \multicolumn{5}{|l|}{ Intraoperative data } \\
\hline Input of fluids, L, mean \pm SD & $5.2 \pm 2.3$ & $5.4 \pm 2.1$ & $\mathrm{n} / \mathrm{a}$ & 0.66 \\
\hline Vasopressor use & $41(23.3)$ & $18(10.2)$ & 59 & 0.024 \\
\hline Hypotension* & $36(20.5)$ & $14(8.0)$ & 50 & 0.017 \\
\hline Red cell transfusion & $24(13.6)$ & $6(3.4)$ & 30 & 0.008 \\
\hline $\begin{array}{l}\text { Estimated blood loss, mL, } \\
\text { median (IQR) }\end{array}$ & $\begin{array}{c}250 \\
(150-350)\end{array}$ & $\begin{array}{c}400 \\
(250-500)\end{array}$ & $\mathrm{n} / \mathrm{a}$ & 0.94 \\
\hline Coupler use & 79 (44.9) & $44(25.0)$ & 123 & 0.008 \\
\hline Anastomotic revision & $15(8.5)$ & $5(2.8)$ & 20 & 0.15 \\
\hline \multicolumn{5}{|l|}{ Probe placement } \\
\hline Artery & $27(27.3)$ & $\mathrm{n} / \mathrm{a}$ & $\mathrm{n} / \mathrm{a}$ & $\mathrm{n} / \mathrm{a}$ \\
\hline Vein & $3(3.0)$ & $\mathrm{n} / \mathrm{a}$ & $\mathrm{n} / \mathrm{a}$ & $\mathrm{n} / \mathrm{a}$ \\
\hline Both & $69(69.7)$ & $\mathrm{n} / \mathrm{a}$ & $\mathrm{n} / \mathrm{a}$ & $\mathrm{n} / \mathrm{a}$ \\
\hline $\begin{array}{l}\text { Primary ischemia time, min, } \\
\text { mean } \pm \mathrm{SD}\end{array}$ & $69.4 \pm 23.9$ & $67.6 \pm 29.7$ & $\mathrm{n} / \mathrm{a}$ & 0.80 \\
\hline $\begin{array}{l}\text { Length of surgery, min, } \\
\text { mean } \pm \mathrm{SD}\end{array}$ & $579.8 \pm 155.8$ & $506.2 \pm 150.8$ & $\mathrm{n} / \mathrm{a}$ & 0.46 \\
\hline \multicolumn{5}{|l|}{ Postoperative data } \\
\hline Vasopressor use & $2(1.1)$ & $0(0.0)$ & 2 & 0.50 \\
\hline Hypotension* in the 1 st $72 \mathrm{~h}$ & $17(9.7)$ & $11(6.3)$ & 28 & 0.53 \\
\hline Red cell transfusion & $23(13.1)$ & $14(8.0)$ & 37 & 0.35 \\
\hline $\begin{array}{l}\text { Urine output, } \mathrm{mL} / \mathrm{h}, \\
\text { median (IQR) }\end{array}$ & $77(50-94)$ & $89(60-119)$ & $\mathrm{n} / \mathrm{a}$ & 0.10 \\
\hline Fever $^{\dagger}$ in the $1 \mathrm{st} 72 \mathrm{~h}$ & $18(10.2)$ & $34(19.3)$ & 52 & 0.001 \\
\hline Desaturation ${ }^{\ddagger}$ in the $1 \mathrm{st} 72 \mathrm{~h}$ & $23(13.1)$ & $15(8.5)$ & 38 & 0.45 \\
\hline Death & $0(0.0)$ & $0(0.0)$ & 0 & $\mathrm{n} / \mathrm{c}$ \\
\hline \multicolumn{5}{|l|}{ Anticoagulation use } \\
\hline Enoxaparin & $13(7.8)$ & $7(4.2)$ & 20 & 0.63 \\
\hline ASA & $11(6.6)$ & $23(13.8)$ & 34 & 0.002 \\
\hline Enoxaparin/ASA & $57(34.1)$ & $18(10.8)$ & 75 & 0.0001 \\
\hline Heparin & $6(3.6)$ & $1(0.6)$ & 7 & 0.24 \\
\hline Heparin/ASA & $12(7.2)$ & $5(3.0)$ & 17 & 0.31 \\
\hline None & $1(0.6)$ & $13(7.8)$ & 14 & 0.0001 \\
\hline $\begin{array}{l}\text { Total patients on } \\
\text { anticoagulation }\end{array}$ & 99 (59.3) & $54(32.3)$ & 153 & 0.0001 \\
\hline
\end{tabular}

$\overline{\text { Data presented as } n(\%) \text { unless otherwise indicated }{ }^{*} \text { Mean arterial pressure }}$ $<60 \mathrm{mmHg}$; ${ }^{\dagger}$ Temperature $>101.5 \mathrm{~F}$; ${ }^{\ddagger}$ Oxygen saturation $<92 \%$. ASA Acetylsalicylic acid; n/a Not applicable; n/c Not calculated

Surgical complications were defined as those necessitating a second operative intervention. Complications requiring reoperation were further categorized according to vascular- and non-vascularrelated problems. Vascular-related complications included arterial or venous thrombosis, arterial vasospasm, venous outflow problems and technical anastomotic problems. Non-vascular-related problems included wound-related complications such as wound infection, necrosis, dehiscence, seromas and hematomas. The final outcome for each flap was classified as complete salvage (resulting in no loss of the flap), partial salvage (resulting in partial loss of the flap) or complete failure (resulting in total loss of the flap).

\section{Outcome measures}

Sensitivity and specificity were calculated for each monitoring device with values obtained for true positives, true negatives, false positives and false negatives. They reflect the traditional objective assessment indicators for comparing diagnostic techniques. To account for the time-dependent nature of postoperative free flap monitoring, the flap salvage rate and the false-positive rate were also calculated. These two rates constitute the study's primary outcome measures. The flap
TABLE 4

Flap complications according to monitoring device

\begin{tabular}{lcccc}
\hline Complication & $\begin{array}{c}\text { Internal } \\
\text { Doppler }\end{array}$ & $\begin{array}{c}\text { External } \\
\text { Doppler }\end{array}$ & Total, $\mathbf{n}$ & $\mathbf{P}$ \\
\hline Flaps & $101(57.4)$ & $75(42.6)$ & 176 & 0.56 \\
Nonvascular & $14(13.9)$ & $10(13.3)$ & 24 & 0.16 \\
$\quad$ Hematoma & $8(7.9)$ & $2(2.7)$ & 10 & 0.03 \\
Necrosis & $1(1.0)$ & $1(1.3)$ & 2 & 1.00 \\
Infection & $3(3.0)$ & $6(8.0)$ & 9 & 0.46 \\
Wound dehiscence & $2(2.0)$ & $0(0.0)$ & 2 & 0.23 \\
Seroma & $0(0.0)$ & $0(0.0)$ & 0 & 1.00 \\
Other nonvascular & $0(0.0)$ & $1(1.3)^{\star}$ & 1 & 1.00 \\
Vascular & $8(7.9)$ & $12(16.0)$ & 20 & 0.29 \\
$\quad$ Venous congestion & $1(1.0)$ & $3(4.0)$ & 4 & 1.00 \\
$\quad$ Vessel thrombosis & $4(4.0)$ & $7(9.3)$ & 11 & 0.49 \\
$\quad$ Vein & $3(3.0)$ & $6(8.0)$ & 9 & 0.46 \\
$\quad$ Artery & $1(1.0)$ & $1(1.3)$ & 2 & 1.00 \\
Arterial vasospasm & $1(1.0)$ & $1(1.3)$ & 2 & 1.00 \\
$\quad$ Other vascular & $1(1.0)^{\dagger}$ & $1(1.3)^{\ddagger}$ & 2 & 1.00 \\
$\quad$ Venous obstruction & $1(1.0)$ & $0(0.0)$ & 1 & 1.00 \\
Technical anastomotic & $0(0.0)$ & $0(0.0)$ & 0 & 1.00 \\
$\quad$ problems & & & & \\
Overall number of flap & $22(21.8)$ & $22(29.3)$ & 44 & 0.29 \\
$\quad$ complications & & & & \\
Total re-explorations & $19(18.8)$ & $22(29.3)$ & 41 & 0.10 \\
\hline Data presented as n & & & &
\end{tabular}

Data presented as $n(\%)$ unless otherwise indicated. *Orocutaneous fistula; ${ }^{\dagger}$ Compression of venous pedicle by internal Doppler probe; ${ }^{\ddagger}$ Extrinsic compression of arterial anastomosis

TABLE 5

Flap survival and losses according to monitoring device

\begin{tabular}{lcccl}
\hline \multicolumn{5}{c}{ Internal Doppler } \\
\hline A) External Doppler Total, $\mathbf{n}$ & $\mathbf{P}$ \\
Overall flap survival & $99(98.0)$ & $67(89.3)$ & 166 & 0.26 \\
$\quad$ No flap loss & $95(94.1)$ & $61(81.3)$ & 156 & 0.015 \\
$\quad$ Partial flap loss & $4(3.96)$ & $6(8.00)$ & 10 & 0.33 \\
Compromised flaps & $22(21.8)$ & $22(29.3)$ & 44 & 0.29 \\
$\quad$ Salvaged flaps & $20(90.9)$ & $14(63.6)$ & 34 & 0.068 \\
Total flap loss & $2(2.0)$ & $8(10.7)$ & 10 & 0.02 \\
B) & & & & \\
Overall flap survival & $99(98.0)$ & $67(89.3)$ & 166 & 0.03 \\
Total flap loss & $2(2.0)$ & $8(10.7)$ & 10 & \\
\hline
\end{tabular}

Data presented as $n$ (\%) unless otherwise indicated

salvage rate is the proportion of compromised flaps that was salvaged with reoperation and reflects the effectiveness of the respective monitoring device in early detection of vascular compromise (6). The false-positive rate is the number of compromised flaps with false positive alarms divided by the total number of uncompromised flaps and reflects unnecessary re-exploration in the absence of true vascular compromise (6). The secondary outcome measure calculated was the false negative rate. This is the proportion of flaps without an alarm from the respective monitoring device that was found to have vascular compromise on re-exploration. The decision to re-explore false-negative cases was based on clinical diagnosis of flap compromise in the absence of a device alarm. Clinical changes suggestive of flap compromise included altered appearance and colour, temperature and capillary refill despite the absence of a change in signal for flaps monitored by either the ED or ID probe.

Statistical analysis

Continuously distributed outcomes were summarized with the sample size, mean, standard deviation, median, minimum and maximum and categorical outcomes were summarized with counts, percentages and 
TABLE 6

Postoperative outcome measures according to monitoring device

\begin{tabular}{|c|c|c|c|c|}
\hline & Internal Doppler & External Doppler & Total & $\mathbf{P}$ \\
\hline Number of flaps, n (\%) & $101(57.4)$ & $75(42.6)$ & 176 & 0.56 \\
\hline \multicolumn{5}{|l|}{ Descriptive statistics } \\
\hline $\mathrm{FP}, \mathrm{n}$ & 0 & 2 & 2 & $\mathrm{n} / \mathrm{a}$ \\
\hline $\mathrm{TP}, \mathrm{n}$ & 10 & 8 & 18 & $\mathrm{n} / \mathrm{a}$ \\
\hline $\mathrm{FN}, \mathrm{n}$ & 0 & 1 & 1 & $\mathrm{n} / \mathrm{a}$ \\
\hline $\mathrm{TN}, \mathrm{n}$ & 91 & 64 & 155 & $\mathrm{n} / \mathrm{a}$ \\
\hline Sensitivity, TP/TP+FN, \% (95\% Cl) & $100(69-100)$ & $89(52-98)$ & $\mathrm{n} / \mathrm{a}$ & $\mathrm{n} / \mathrm{a}$ \\
\hline Specificity, TN/TN+FP, \% (95\% Cl)* & $100(96-100)$ & $97(89-100)$ & $\mathrm{n} / \mathrm{a}$ & $\mathrm{n} / \mathrm{a}$ \\
\hline Positive predictive value, TP/TP+FP, \% (95\% Cl) & $100(69-100)$ & $80(44-97)$ & $\mathrm{n} / \mathrm{a}$ & $\mathrm{n} / \mathrm{a}$ \\
\hline Negative predictive value, TN/TN+FN, \% (95\% Cl) & $100(96-100)$ & $98(92-100)$ & $\mathrm{n} / \mathrm{a}$ & $\mathrm{n} / \mathrm{a}$ \\
\hline \multicolumn{5}{|l|}{ Primary outcome measures } \\
\hline Flap salvage rate (salvaged flaps/compromised flaps), \% (n/n) & $90.9(20 / 22)$ & $63.6(14 / 22)$ & & 0.068 \\
\hline FP rate (FP/uncompromised flaps), \% (n/n) & $0.0(0 / 99)$ & $3.0(2 / 67)$ & & 0.18 \\
\hline \multicolumn{5}{|l|}{ Secondary outcome measure } \\
\hline FN rate (FN/compromised flaps), \% (n/n) & $0.0(0 / 22)$ & $4.5(1 / 22)$ & & 1.00 \\
\hline
\end{tabular}

FN False negative; FP False positive; n/a Not applicable; TN True negative; TP True positive

other nonparametric variables. For the comparison of means between subjects with and without complications, a Student's $t$ test or Fisher's exact test were used as deemed appropriate. The Mann-Whitney U-test was used for comparison of medians. For categorical data, Pearson's $\chi^{2}$ test or Fisher's exact test were used. All statistical testing was two-sided with a significance level of 5\%. SPSS version 19.0 (IBM Corporation, USA) and SigmaXL (SigmaXL Inc, Canada) were used for the analysis.

\section{Microsurgical details}

For the ID group, the Cook-Swartz ID flow system (Cook Medical, Cook Ireland Ltd, Ireland) was used. The probe was applied to either the venous $(3 \%)$ or arterial $(27.3 \%)$ pedicle with a silicone cuff and secured in place with suture or microclips. For the remainder of the flaps in this group $(69.7 \%)$, separate probes were used on both the artery and the vein. For the ED group, the device was applied to the surface of the skin to detect perfusion of the underlying vascular pedicle. The location of the vascular pedicle was marked at the end of surgery on the skin with a superficial suture or a surgical marker protected by a clear adhesive dressing. This allowed nursing staff and other members of the care team to use this landmark for frequent flap checks postoperatively.

All patients following microsurgical free tissue transfers were admitted to the surgical intensive care unit (SICU) at University Hospital. All flaps were monitored clinically in the postoperative period. Nursing staff routinely performed hourly clinical examinations while patients were in the SICU. In particular, they were instructed to monitor the venous outflow for clinical signs of venous congestion. Additionally, the patency of the flap's vascular pedicle was assessed with either the ID probe placed at the time of surgery (continuous signal) or the ED device (hourly). The decision to apply either device was made by the performing surgeon based on anatomic considerations, the type of flap created and preference based on previous training and experience.

Any suspicion of flap compromise by the nursing staff, either by a change in the clinical examination or loss or change in the intensity of the Doppler signal, prompted review by the resident or surgical faculty on call. The decision to reoperate was based on the surgeon's overall clinical judgment. Clinical monitoring of flaps continued until the patient was discharged from the hospital. The ID group was monitored continuously until discharged home and the probe wire was removed at the bedside before discharge. Patients in the ED group were monitored every hour while in the SICU, then every $2 \mathrm{~h}$ to $4 \mathrm{~h}$ on a general surgical ward until discharged home.

\section{RESULTS}

Of the 176 flaps performed in the present study, 101 flaps (57.4\%) were monitored in the ID group and 75 flaps $(42.6 \%)$ in the ED group. Seventy-eight flaps $(77.2 \%)$ in the ID group and 50 flaps $(66.7 \%)$ in the ED group were performed for nontraumatic indications $(\mathrm{P}=0.13)$. There were no significant differences between the number in each monitoring group $(\mathrm{P}=0.56)$ as well as in the demographic characteristics between the two groups (Table 1). The rectus abdominis flap was the most common type of flap performed in both groups. Significantly more rectus abdominis (ID 20.5\%, ED 23.9\%; $\mathrm{P}=0.01$ ) and anterolateral thigh flaps (ID $17 \%, \mathrm{ED} 0.6 \% ; \mathrm{P}=0.0001$ ) were performed in the ID group. There were no significant differences in the number of other types of flaps between the two groups (Table 2). The ID group had a larger proportion of fasciocutaneous flaps $(38.6 \%$, versus ED $4.0 \%$; $\mathrm{P}=0.0001)$ and the ED group had more myocutaneous flaps $(85.3 \%$, versus ID $50.5 \% ; \mathrm{P}=0.0001$ ).

Intraoperatively, more patients in the ID group had venous anastomoses created with a coupler device (ID 44.9\%, ED 25\%; P=0.008). Patients in the ID group were more frequently hypotensive with a mean arterial pressure $<60 \mathrm{mmHg}$ (ID 20.5\%, ED 8.0\%; $\mathrm{P}=0.017$ ) and administered vasopressors (ID 23.3\%, ED 10.2\%; $\mathrm{P}=0.024$; Table 3). While there was no difference in the number of patients receiving intraoperative fluids, more patients in the ID group were administered blood for transfusion (ID 13.6\%, ED 3.4\%; $\mathrm{P}=0.008$ ). However, there were no differences between the groups with anastomotic revision rates (ID $8.5 \%, \mathrm{ED} 2.8 \% ; \mathrm{P}=0.15$ ) and the length of initial surgery (ID $579.8 \mathrm{~min}$, ED $506.2 \mathrm{~min} ; \mathrm{P}=0.46$ ). Additionally, there were no differences in the use of vasopressors (ID 1.1\%, ED 0.0\%; $\mathrm{P}=0.50$ ) and blood transfusions (ID $13.1 \%, \mathrm{ED} 8.0 \% ; \mathrm{P}=0.35$ ) in the postoperative period. Postoperatively, more patients in the ED group experienced febrile episodes (ID 10.2\%, ED 19.3\%; P=0.001). Additionally, patients in the ID group were more frequently placed on various anticoagulant regimens in the postoperative period (ID 59.3\%, ED 32.3\%; P=0.0001) while those in the ED group were more likely not to have received postoperative anticoagulation (ID 0.6\%, ED 7.8\%; $\mathrm{P}=0.0001$ ). There were no other significant differences in intraoperative or postoperative characteristics between the groups (Table 3).

Of the 44 flaps in the study with complications, one-half were in the ID group and the other one-half in the ED group (ID 21.8\%, ED 29.3\%; $\mathrm{P}=0.29$; Table 4). Regarding the specific postoperative flap complications, the number of hematomas was significantly higher in the ID group than in the ED group (ID 7.9\%, ED 2.7\%; $\mathrm{P}=0.03$ ). Comparison of other vascular and nonvascular complications revealed no significant differences in the number of flaps between the two groups (Table 4). 


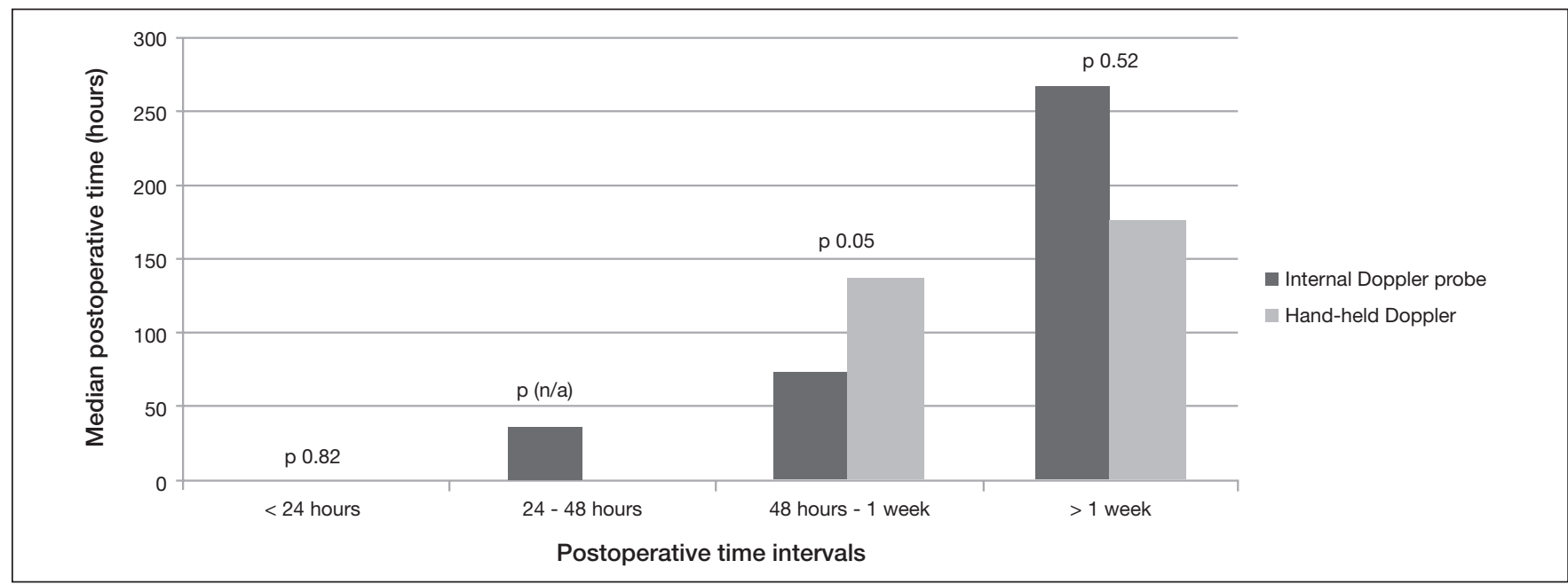

Figure 1) Postoperative time to reexploration as a function of type of monitoring device used

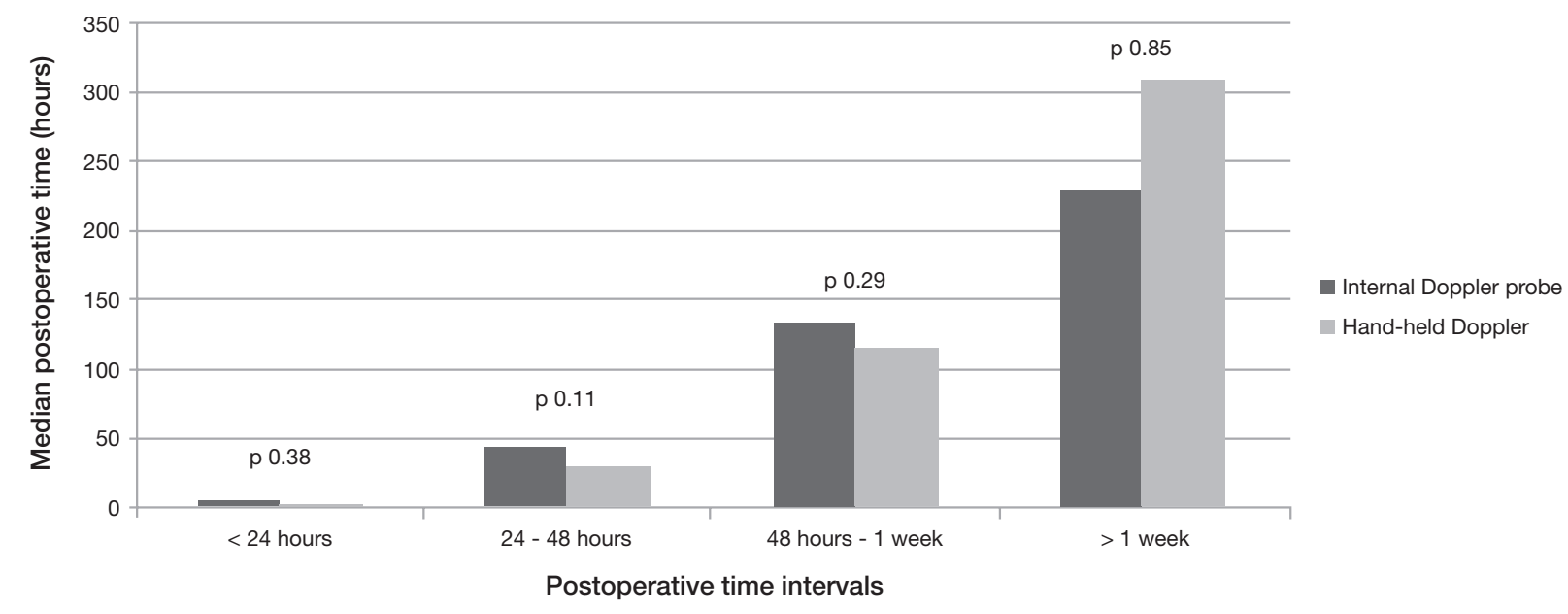

Figure 2) Timing of complications detected as a function of type of monitoring device used

In the ID group, three of the 22 flaps with complications were not re-explored (Table 4). The first was a rectus abdominis flap to the lower extremity that developed a minor infection and was successfully treated nonoperatively. The second was a latissimus dorsi flap to the face that developed a hematoma after removal of a suction drain. The flap was clinically assessed by the faculty attending and it was concluded that the hematoma was not a threat to the viability of the flap. This flap was successfully treated by conservative means. The third flap was for a patient who became hemodynamically unstable in the postoperative period in the SICU. The patient was considered to be too unstable for re-exploration and received appropriate resuscitation in the SICU. Both patient and flap ultimately survived. In the ED group, all 22 flaps with complications were re-explored.

Flap survival and losses are summarized in Table 5. There was a significant difference in overall flap survival (ID 98.0\% versus ED $89.3 \%$ ) and total flap loss (ID 2.0\% versus ED 10.7\%) on $\chi^{2}$ analysis between the two groups $(\mathrm{P}=0.03)$.

Postoperative outcome measures are summarized in Table 6. The number of compromised flaps did not differ (ID 21.8\%, ED 29.3\%; $\mathrm{P}=0.29$; Table 5), as did the proportion of flaps that was successfully salvaged (ID 90.9\%, ED 63.6\%; P=0.068; Tables 5 and 6). There were no significant differences between the two groups for the false-positive (ID 0\%, ED 3\%; P=0.18) and false-negative rate (ID 0.0\%, ED 4.5\%; $\mathrm{P}=1.0$ ). Similarly, there were no significant differences in the median time to detection of complications (ID $55.4 \mathrm{~h}$, ED $52.7 \mathrm{~h} ; \mathrm{P}=0.22$ ), median time to re-operation after detection of complications (ID $7.5 \mathrm{~h}$,
ED $2.9 \mathrm{~h} ; \mathrm{P}=0.40)$ and the median postoperative time to re-exploration (75.5 h, ED 96.2 h; P=0.43; Table 7). However, on analysis of complications occurring $48 \mathrm{~h}$ to one week after initial surgery, the median postoperative time to re-exploration was significantly less in the ID group (ID $74.5 \mathrm{~h}$, ED $136.8 \mathrm{~h} ; \mathrm{P}=0.05$ ) than the ED group (Table 8 , Figures 1 to 4 ). The most common cause in this postoperative period discovered on re-exploration was flap hematoma with extrinsic compression of the vascular pedicle for the ID group (Table 9) and flap infection for the ED group (Table 10).

\section{DISCUSSION}

Microvascular free tissue transfer is a highly successful technique for coverage of large tissue defects throughout the body. Although successful, the consequences of flap failure can be very costly to remedy, emotionally devastating to the patient with the prospect of repeating major surgery and professionally detrimental to the reconstructive surgeon $(12,13)$. Whether the use of the ID probe offers an advantage over the ED device in increasing flap salvage rates continues to be debated in the medical literature (6-8). The purpose of the present study was to compare the effectiveness of the two monitoring devices in reducing the time to detection of complications and the time to re-operation resulting in a higher rate of salvage of failing flaps.

The sensitivity of the ID was found to be superior to that of the ED ( $100 \%$ versus $89 \%$; Table 6). This substantiates our finding of a lower false negative rate for the ID (ID 0.0\%, ED 4.5\%) and implies that this device is superior for postoperative screening of vascular complications. 


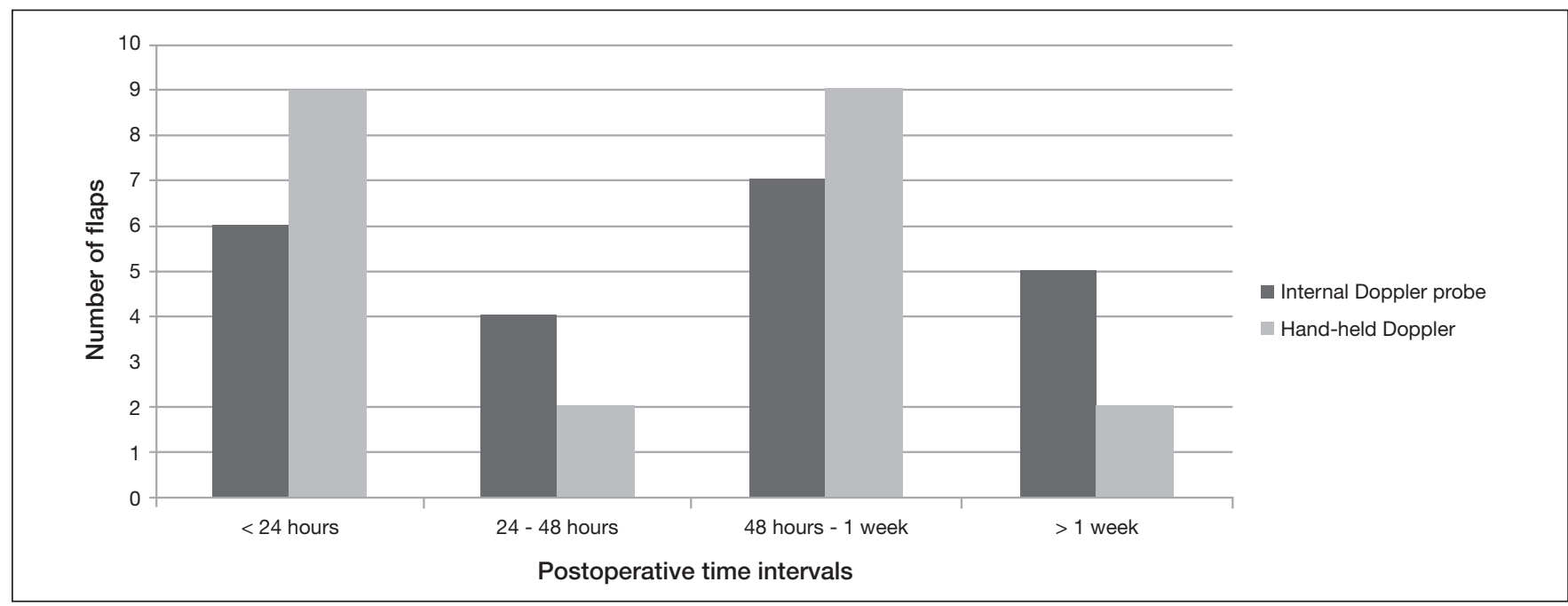

Figure 3) Number of flaps with complications as a function of type of monitoring device used and postoperative time to detection after initial surgery

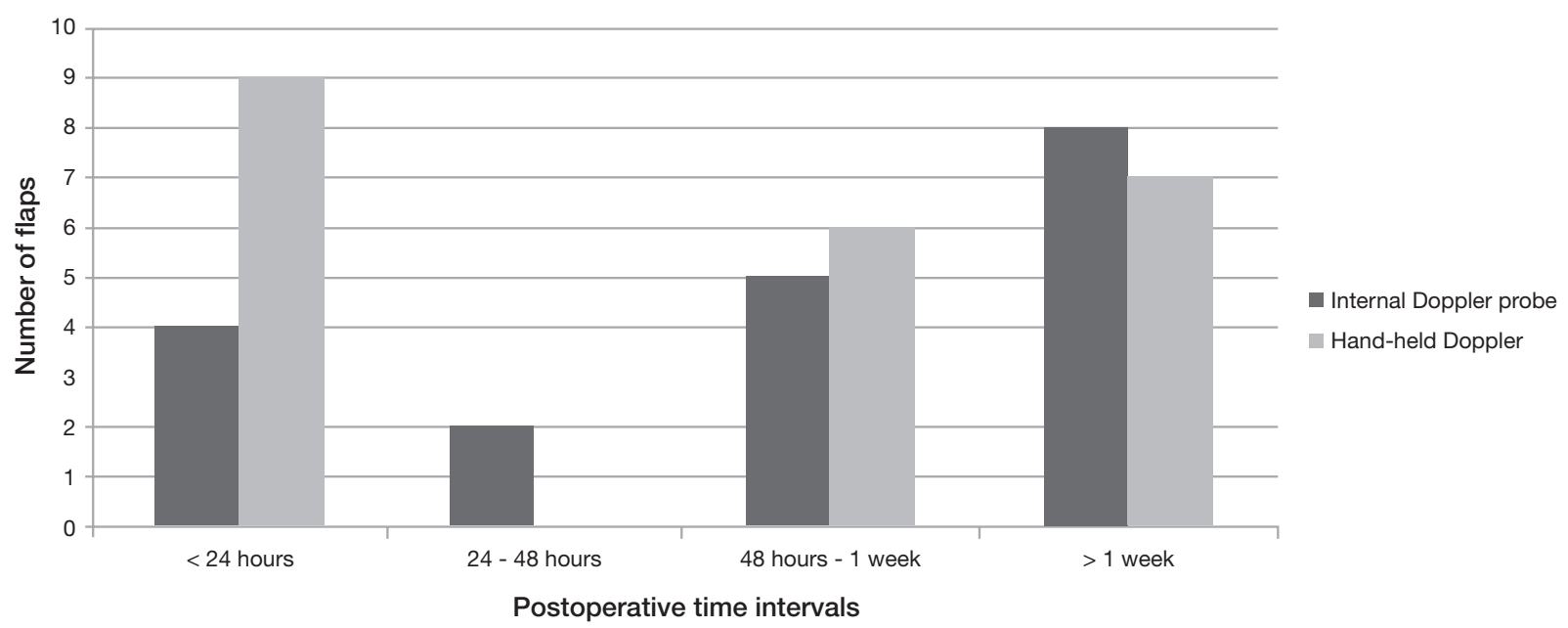

Figure 4) Number of flaps requiring reoperation as a function of type of monitoring device used and postoperative time to re-exploration

However, the difference in the false-negative rates for the two devices was not statistically significant $(\mathrm{P}=1.0)$. Additionally, the calculated specificities were also comparable (ID 100\%, ED 97\%). The low falsepositive rates (ID 0\%, ED 3\%) found in the present study imply that the monitors were not likely to detect vascular compromise incorrectly leading to few unnecessary interventions. They were consistent with the high specificities but the difference was also not significant $(\mathrm{P}=0.18)$. These findings together indicate that both devices are effective for postoperative screening of free flaps for vascular complications and are reliable indicators for diagnosing the presence of complications. The study also found high positive (ID 100\%, ED $80 \%$ ) and negative predictive values (ID 100\%, ED 98\%) for both devices. Therefore, in the face of a positive alarm from either device, the surgeon should proceed with re-exploration of the flap to confirm the presence of a vascular complication and correct the defect before irreversible tissue loss can occur.

The sensitivity of the ID has been reported as $100 \%$ in several previous studies (16). Swartz and colleagues noted an improvement in sensitivity from $66.7 \%$ to $100 \%$ when the probe was used for monitoring the venous pedicle rather than the artery (17). Specificity of the ID has been a subject of more debate since studies before 2006 quoted a wide range for the false-positive rate, up to $88 \%$ (16). However, it is evident that the high false-positive rate in those older studies was due to the learning curve for interpretation associated with introduction of the device into clinical practice because more recent studies quote specificity as high as $98.7 \%(16-19)$. Therefore, departments whose staff are experienced in the use of the ID can be confident in their interpretation of a signal alarm and proceed with re-exploration. With less experienced staff, it may still be necessary to consider use of a complementary test in ambivalent cases, such as bedside colour Duplex flowmetry, before proceeding with re-exploration $(10,16,20)$. In both scenarios, it is always prudent to base the final decision to reexplore on the overall clinical condition of the patient and the flap.

Because study of the ED has been traditionally included in clinical postoperative monitoring of free flaps, dedicated sensitivity and specificity values are infrequently documented in the literature. Therefore, a comparison with previous studies in terms of these indices is not possible for this device.

The problem with descriptive statistical analysis is that it is does not acknowledge the time-dependent nature of postoperative monitoring of free flaps. In this regard, we identified the primary outcome measures (flap salvage rate, false positive rate) for this study as outlined by Whitaker et al (6) and Lineweaver (7). These are true measures of the effectiveness of a monitoring device because they are independent of the surgeon's decision making (6). We identified the false-negative rate as the secondary outcome measure because it is a theoretical index of the effectiveness of a monitoring device. However, it is dependent on the surgeon's decision to reoperate in the case of a positive alarm from the respective device and is, therefore, more subjective (6). 
TABLE 7

Timing of detected complications and reoperation according to monitoring device

\begin{tabular}{lccc}
\hline Interval, $\mathbf{h}$ & Internal Doppler & External Doppler & $\mathbf{P}$ \\
\hline Time to detection of complications & & \\
Mean \pm SD & $111.2 \pm 148.6$ & $79.1 \pm 93.9$ & 0.34 \\
Median (range) & $55.4(1.8-639.2)$ & $52.7(0.7-395.2)$ & 0.22 \\
Time to reoperation after detection of complications & \\
Mean \pm SD & $39.9 \pm 63.7$ & $35.8 \pm 76.4$ & 1.00 \\
Median (range) & $7.5(0.8-189.6)$ & $2.9(0.2-336.6)$ & 0.40 \\
Postoperative time to re-exploration (time to detection + time to reoperation) \\
Mean \pm SD & $154.1 \pm 195.3$ & $113.3 \pm 131.1$ & 0.43 \\
Median (range) & $75.5(2.8-828.8)$ & $96.2(1.4-469.5)$ & 0.43 \\
\hline
\end{tabular}

TABLE 9

Flap complications requiring reoperation for the implantable Doppler group according to postoperative time to re-exploration

\begin{tabular}{|c|c|c|c|}
\hline $\begin{array}{l}\text { Postoperative time to } \\
\text { re-exploration }\end{array}$ & Complications per flap & Corrective procedure & Survival \\
\hline \multirow[t]{4}{*}{$<24 \mathrm{~h}$} & Venous thrombosis & Microsurgical revision of venous anastomosis & Yes \\
\hline & Venous thrombosis & Microsurgical revision of venous anastomosis & Yes \\
\hline & Venous thrombosis & Microsurgical revision of arterial and venous anastomosis & Yes \\
\hline & Hematoma & Hematoma evacuation & Yes \\
\hline \multirow[t]{2}{*}{$24 \mathrm{~h}$ to $48 \mathrm{~h}$} & Hematoma & Hematoma evacuation & Yes \\
\hline & Hematoma & Wound exploration with ligation of bleeding vessels & Yes \\
\hline \multirow[t]{5}{*}{$48 \mathrm{~h}$ to 1 week } & Hematoma with pedicle compression & Hematoma evacuation & Yes \\
\hline & Hematoma, arterial vasospasm & Hematoma evacuation, revision of arterial anastomosis & Yes \\
\hline & Hematoma, venous compression by internal Doppler probe & $\begin{array}{l}\text { Hematoma evacuation, repositioning of Cook catheter probe on } \\
\text { venous pedicle }\end{array}$ & Yes \\
\hline & Flap infection & Nonoperative treatment & Yes \\
\hline & Hematoma with pedicle compression & Hematoma evacuation & Yes \\
\hline \multirow[t]{8}{*}{$>1$ week } & Arterial thrombosis & Removal of nonviable flap & No \\
\hline & Hematoma & Hematoma evacuation & Yes \\
\hline & Flap infection & Debridement & No \\
\hline & Flap necrosis & Debridement & Yes \\
\hline & Wound dehiscence & Debridement & Yes \\
\hline & Venous congestion & Microsurgical revision of venous anastomosis & Yes \\
\hline & Wound dehiscence & Flap re-insetted & Yes \\
\hline & Flap infection & Debridement & Yes \\
\hline
\end{tabular}

In the present study, the difference in the flap salvage rate was not significant (ID 90.9\% versus ED 63.6\%; $\mathrm{P}=0.068$ ). This is the second study that has sought to compare the effectiveness of the ID with the ED. The first study by Lohman et al (14) examined 38 consecutive patients with free flaps with only five developing signs of vascular compromise in the postoperative period. Two of these flaps had a diminished signal from the ID monitor and a third had diminished signals from both ID and ED devices. Kind et al demonstrated a flap salvage rate of $100 \%$ and a false-positive rate of $3.4 \%$ for the ID in their series of 147 free flaps in 135 patients monitored with this device, results comparable to our own findings (21). Both of these studies were limited by a small number of compromised flaps making the conclusions susceptible to type II error. In our study, we examined 176 flaps with a larger number of complications in either group and should, therefore, be able to make a more definitive analysis of the findings. However, the difference in the flap salvage rate was not significant. We anticipate with further study in a larger series of patients, this difference would show greater statistical significance.

The overall flap survival rate in the ID group (98\%) was comparable to that of the ED group (89.3\%) and did not differ significantly $(\mathrm{P}=0.26)$.
TABLE 8

Time intervals to detection of complications and the postoperative period to re-exploration according to monitoring device

\begin{tabular}{lccccc}
\hline $\begin{array}{l}\text { Postoperative time } \\
\text { intervals }\end{array}$ & ID, $\mathbf{n}$ & ED, $\mathbf{n}$ & $\begin{array}{c}\text { ID median } \\
\text { time, } \mathbf{~}\end{array}$ & $\begin{array}{c}\text { ED median } \\
\text { time, } \mathbf{~}\end{array}$ & $\mathbf{P}$ \\
\hline $\begin{array}{l}\text { Time to detection } \\
\text { <24 h }\end{array}$ & 6 & 9 & 6.6 & 3.1 & 0.38 \\
24 h to 48 h & 4 & 2 & 44.5 & 31 & 0.11 \\
48 h to 1 week & 7 & 9 & 134.8 & 115.6 & 0.29 \\
>1 week & 5 & 2 & 230.5 & 308.7 & 0.85 \\
Postoperative time to re-exploration* & & & \\
<24 h & 4 & 9 & 0.4 & 0.6 & 0.82 \\
24 h to 48 h & 2 & 0 & 36.2 & $\mathrm{n} / \mathrm{a}$ & $\mathrm{n} / \mathrm{a}$ \\
48 h to 1 week & 5 & 6 & 74.5 & 136.8 & 0.05 \\
>1 week & 8 & 7 & 266.1 & 176 & 0.52 \\
\hline
\end{tabular}

*See Tables 9 and 10. ED External Doppler; ID Internal Doppler; n/a Not applicable
This is not an indicator of the effectiveness of the postoperative monitoring device but rather the quality of the initial surgery (7). However, the proportion of flaps suffering total loss was higher in the ED group than for the ID (ID 2.0\% versus ED 10.7\%; $\mathrm{P}=0.03$; Table 5). Additionally, there were more complications for the ID group with successful salvage on reoperation occurring up to one week into the postoperative period (Table 9) while there were more instances of unsuccessful salvage for the ED group in the same time period (Table 10). Our study also revealed several instances of slowly accumulating flap hematomas in the ID group as evidenced by their detection in the postoperative time period $48 \mathrm{~h}$ to one week. Several of the flaps with total losses in the ED group were due to flap infections and one hematoma (Table 10). It is possible that hematomas were not recognized early enough in the ED group compared with the ID group leading to subclinical vascular compromise and the onset of more wound-related complications in the late postoperative period. Furthermore, four of the five complications for the ID group in the $48 \mathrm{~h}$ to one week postoperative period were associated with signal changes that were true positives (three venous and one arterial), resulting in successful salvage of all flaps. There were six flap complications for the same time period in the 
TABLE 10

Flap complications requiring reoperation for the external Doppler group according to postoperative time to re-exploration

\begin{tabular}{|c|c|c|c|}
\hline $\begin{array}{l}\text { Postoperative time to } \\
\text { re-exploration }\end{array}$ & Complications per flap & Corrective procedure & Survival \\
\hline \multirow[t]{9}{*}{$<24 \mathrm{~h}$} & Venous congestion & Removal of nonviable flap & Yes \\
\hline & Arterial thrombosis & Microsurgical revision of arterial and venous anastomosis & Yes \\
\hline & Arterial vasospasm & Microsurgical revision of arterial and venous anastomosis & Yes \\
\hline & Venous thrombosis & Microsurgical revision of venous anastomosis & Yes \\
\hline & Hematoma & Hematoma evacuation & Yes \\
\hline & Venous thrombosis & Microsurgical revision of arterial and venous anastomosis & Yes \\
\hline & Extrinsic compression of arterial anastomosis & Flap re-insetted with partial excision of compressing pectoralis major & Yes \\
\hline & Venous congestion & Microsurgical revision of venous anastomosis & Yes \\
\hline & Venous thrombosis & Microsurgical revision of venous anastomosis & Yes \\
\hline $24 \mathrm{~h}$ to $48 \mathrm{~h}$ & No complications detected & & \\
\hline \multirow[t]{6}{*}{$48 \mathrm{~h}$ to 1 week } & Flap infection & Debridement & No \\
\hline & Flap infection & Incision, drainage and debridement & No \\
\hline & Venous thrombosis & Arterial/venous anastomotic thrombectomy, revision, debridement & No \\
\hline & Flap infection & Incision, drainage and debridement & Yes \\
\hline & Flap infection & Incision, drainage and debridement & No \\
\hline & Venous thrombosis & Microsurgical revision of venous anastomosis & No \\
\hline \multirow[t]{7}{*}{$>1$ week } & Venous thrombosis & Debridement with delayed flap sectioning & Yes \\
\hline & Flap necrosis & Debridement & Yes \\
\hline & Venous congestion & Debridement & Yes \\
\hline & Hematoma & Hematoma evacuation with debridement & No \\
\hline & Orocutaneous fistula & Flap reconstruction & Yes \\
\hline & Flap infection & Debridement & No \\
\hline & Flap infection & Debridement & No \\
\hline
\end{tabular}

ED group with only two associated with signal changes. Only one of the six flaps survived and for this flap, there was no abnormality in the ED signal before clinical detection. One possible explanation for these differences is that the ID was able to reduce the median postoperative time to re-exploration in the period $48 \mathrm{~h}$ to one week after initial surgery (ID 74.5 h, ED 136.8 h; P=0.05; Table 8; Figure 1), thereby reducing secondary ischemia times for those flaps and avoiding irreversible tissue necrosis. Previous studies have recommended close postoperative monitoring of free flaps for the first $48 \mathrm{~h}$ to $72 \mathrm{~h}$ and at least one other study advocated for monitoring for up to one week $(1,22)$. Our analysis suggests a benefit for monitoring with the ID for up to one week to maximize the opportunity to salvage flaps with later onset of complications.

There were several limitations to our study. This was a retrospective chart review for flaps performed at our single institution over an eightyear period. This may introduce bias into our analysis. Unfortunately, most of the studies in the past 30 years examining the issue of postoperative monitoring of free flaps have been retrospective in design with small numbers of patients enrolled and occurrences of flap failures $(2,13,23,24)$.

The second limitation was the difference in the type of flaps performed with the ID group having more fasciocutaneous flaps and the ED group having predominantly myocutaneous flaps. The critical ischemia time is the maximum duration that a flap can tolerate complete loss of perfusion and remain viable once circulation is restored and is dependent on the types of tissue that constitute the flap (15). Skeletal muscle is most susceptible and in myocutaneous flaps, the average primary critical ischemia time is $9 \mathrm{~h}$ while the average secondary critical ischemia time is $11 \mathrm{~h} \mathrm{(15).} \mathrm{Fasciocutaneous} \mathrm{flaps} \mathrm{are} \mathrm{more}$ resistant to the effects of ischemia and therefore can tolerate a longer critical ischemia time (15). Therefore, flaps in the ED group for the present study would be more susceptible to flap losses with potential for confounding the results of our analysis.

Another potential confounding factor was the difference between groups in the use of intraoperative anastomotic coupler devices for the venous pedicle. These devices assist the surgeon to reduce the primary ischemia time associated with performing a traditional hand-sewn anastomosis (25). They also facilitate the creation of anastomoses with moderate vessel diameter discrepancy and the surgeon is better able to inspect the everted ends of the vessels before final closure (25). The disadvantages associated with use of venous couplers include vessel twisting and endothelial trauma when applying the device (25). Despite these problems, several series have shown that the failure rates for sutured and coupled venous anastomoses are similar $(4,25)$. The effect of this confounding factor on our results should be minimal.

Intraoperatively, there were also differences in the number of patients with hypotension, vasopressor use and administration of blood transfusions. However, there were no differences in the length of initial surgery and postoperative use of vasopressors and blood. Therefore, the difference in intraoperative resuscitative measures resulted in no significant differences in the same indices in the postoperative period.

The focus of the present study was not to explain problems of interpretation of the devices by less experienced staff. However, we found that our nurses had difficulty interpreting a positive signal from the venous probe. We started using the ID by applying separate probes to the arterial and venous pedicles. Detection by the ID depends on which pedicle is being monitored. Venous probes have been found to be able to detect venous occlusion immediately and arterial occlusion within a mean $( \pm S D)$ time of $6 \pm 2.4 \min (3,26)$. Arterial probes can detect arterial occlusion immediately but detection of venous occlusion is delayed to $220 \pm 40 \mathrm{~min}(3,26)$. However, we became concerned for the potential that nurses would rely solely on flawed interpretation of the venous signal at the exclusion of clinical judgment. The goal in all cases was to monitor the flap closely to detect vascular compromise as soon as possible. Further study into the differences in interpretation by various members of the postoperative care team would be beneficial. Additionally, the application of the probe to various pedicles could introduce selection bias into the results obtained.

Finally, the higher proportion of patients on anticoagulant therapy in the ID group might have been responsible for the increased number of hematomas detected. Ninety-five percent of reconstructive surgeons use some type of anticoagulation regimen following free tissue transfers (4). Several previous studies have shown that the risk of hematoma 
formation with most anticoagulation regimens is low except with the use of high-dose heparin treatment. Considering that a higher proportion of our ID group was placed on this type of therapy compared with the ED group, the use of anticoagulation might be a potential confounding factor.

\section{CONCLUSION}

There was no difference in the flap salvage rate between the groups. Our analysis over an eight-year period suggests a potential benefit for the ID with a lower postoperative time to re-exploration in the period $48 \mathrm{~h}$ to one week after initial surgery. Due to the small number of positive results characteristic of studies of this type, there was difficulty in attaining statistical power as well as controlling for potential confounding factors. A prospective randomized controlled trial with larger

\section{REFERENCES}

1. Bui DT, Cordeiro PG, Hu QY, Disa JJ, Pusic A, Mehrara BJ. Free flap reexploration: Indications, treatment, and outcomes in 1193 free flaps. Plast Reconstr Surg 2007;119:2092-100.

2. Chen KT, Mardini S, Chuang DC, et al. Timing of presentation of the first signs of vascular compromise dictates the salvage outcome of free flap transfers. Plast Reconstr Surg 2007;120:187-95.

3. Cusano A, Fernandes R. Technology in microvascular surgery. Oral Maxillofac Surg Clin North Am 2010;22:73-90.

4. Salgado CJ, Moran SL, Mardini S. Flap monitoring and patient management. Plast Reconstr Surg 2009;124(6 Suppl):e295-302.

5. Smit JM, Acosta R, Zeebregts CJ, Liss AG, Anniko M, Hartman EH. Early reintervention of compromised free flaps improves success rate. Microsurgery 2007;27:612-6.

6. Whitaker IS, Rozen WM, Chubb D, et al. Postoperative monitoring of free flaps in autologous breast reconstruction: A multicenter comparison of 398 flaps using clinical monitoring, microdialysis, and the implantable Doppler probe. J Reconstr Microsurg 2010;26:409-16.

7. Lineaweaver W. Techniques of monitoring buried fasciocutaneous free flaps. Plast Reconstr Surg 2009;124:1729-31.

8. Schmulder A, Gur E, Zaretski A. Eight-year experience of the Cook-Swartz Doppler in free-flap operations: Microsurgical and reexploration results with regard to a wide spectrum of surgeries. Microsurgery 2011;31:1-6.

9. Smit JM, Zeebregts CJ, Acosta R, Werker PM. Advancements in free flap monitoring in the last decade: A critical review. Plast Reconstr Surg 2010;125:177-85.

10. Rosenberg JJ, Fornage BD, Chevray PM. Monitoring buried free flaps: Limitations of the implantable Doppler and use of color duplex sonography as a confirmatory test. Plast Reconstr Surg 2006;118:109-13.

11. Abdel-Galil K, Mitchell D. Postoperative monitoring of microsurgical free tissue transfers for head and neck reconstruction: A systematic review of current techniques - part I. Non-invasive techniques. Br J Oral Maxillofac Surg 2009;47:351-5.

12. Rozen WM, Chubb D, Whitaker IS, Acosta R. The efficacy of postoperative monitoring: a single surgeon comparison of clinical monitoring and the implantable Doppler probe in 547 consecutive free flaps. Microsurgery 2010;30:105-10.

13. Selber JC, Angel Soto-Miranda M, Liu J, Robb G. The survival curve: Factors impacting the outcome of free flap take-backs. Plast Reconstr Surg 2012;130:105-13. patient enrollment should be more resistant to the effects of these limitations and hopefully produce more robust conclusions by equivalent comparison of the two devices in the postoperative monitoring of free flaps.

ACKNOWLEDGEMENTS: The authors acknowledge the assistance of Dr Ross Willis (Department of Surgery, University of Texas Health Science Center at San Antonio) for his help in preparing the study's database for statistical analysis and the artwork for publication.

DISCLOSURES: The authors have no financial disclosures or conflicts of interest to declare.

14. Lohman RF, Langevin CJ, Bozkurt M, Kundu N, Djohan R. A prospective analysis of free flap monitoring techniques: Physical examination, external Doppler, implantable Doppler, and tissue oximetry. J Reconstr Microsurg 2013;29:51-6.

15. Siemionow M, Arslan E. Ischemia/reperfusion injury: A review in relation to free tissue transfers. Microsurgery 2004;24:468-75.

16. Bedri MI, Chang BW. Use of the implantable Doppler in free tissue breast reconstruction. Clin Plast Surg 2011;38:309-12.

17. Swartz WM, Izquierdo R, Miller MJ. Implantable venous Doppler microvascular monitoring: Laboratory investigation and clinical results. Plast Reconstr Surg 1994;93:152-63.

18. Poder TG, Fortier PH. Implantable Doppler in monitoring free flaps: A cost-effectiveness analysis based on a systematic review of the literature. Eur Ann Otorhinolaryngol Head Neck Dis 2013;130:79-85.

19. Rozen WM, Ang GG, Acosta R, Rahdon R. Bedside maneuvers and waveform changes in the interpretation of the implantable Doppler probe signal for free-flap monitoring. Microsurgery 2010;30:670-1.

20. Rozen WM, Enajat M, Whitaker IS, Lindkvist U, Audolfsson T, Acosta R. Postoperative monitoring of lower limb free flaps with the Cook-Swartz implantable Doppler probe: A clinical trial. Microsurgery 2010;30:354-60.

21. Kind GM, Buntic RF, Buncke GM, Cooper TM, Siko PP, Buncke HJ Jr. The effect of an implantable Doppler probe on the salvage of microvascular tissue transplants. Plast Reconstr Surg 1998;101:1268-73.

22. Paydar KZ, Hansen SL, Chang DS, Hoffman WY, Leon P. Implantable venous Doppler monitoring in head and neck free flap reconstruction increases the salvage rate. Plast Reconstr Surg 2010;125:1129-34.

23. Abdel-Galil K, Mitchell D. Postoperative monitoring of microsurgical free-tissue transfers for head and neck reconstruction: A systematic review of current techniques - part II. Invasive techniques. Br J Oral Maxillofac Surg 2009;47:438-42.

24. Brown JS, Devine JC, Magennis P, Sillifant P, Rogers SN, Vaughan ED. Factors that influence the outcome of salvage in free tissue transfer. Br J Oral Maxillofac Surg 2003;41:16-20.

25. Yap LH, Constantinides J, Butler CE. Venous thrombosis in coupled versus sutured microvascular anastomoses. Ann Plast Surg 2006;57:666-9.

26. Smit JM, Klein S, de Jong EH, Zeebregts CJ, de Bock GH, Werker PM. Value of the implantable doppler system in free flap monitoring. J Plast Reconstr Aesthet Surg 2012;65:1276-7. 